\title{
Discurso pronunciado por el doctor Rodulfo Camero, Presidente de la Sociedad Colombiana de Obstetricia y Ginecología al instalar el V Congreso Nacional de la Especialidad en la ciudad de Medellín.
}

Señor doctor Mario Aramburo, Gobernador del Departamento;

Doctor Miguel Guzmán, Secretario de Salud;

Doctor Ignacio Vélez Escobar, Rector de la Universidad de Antioquia;

Doctor Oriol Arango, Decano de la Facultad de Medicina;

Doctor Alberto Robledo Clavijo, Presidente de la Academia de Medicina de Medellín;

Doctor Alvaro Arango, Gerente del I.C.S.S.;

Doctor Fernando Gartner, Médico Jefe del I.C.S.S.;

Doctor Pedro Nel Cardona, Presidente del V Congreso Colombiano de Obstetricia y Ginecología;

Doctor René Díaz Correa, Presidente de la Asociación Antioqueña de Obstetricia y Ginecología;

Doctores Arturo Aparicio y Napoleón Franco, Presidentes Honorarios;

Señoras, Colegas:

En el año de 1953, nos reunimos en Bogotá para celebrar la Primera Convención Colombiana de la Especialidad. La Segunda tuvo como sede la alegre ciudad de Cali en el año de 1955. En 1957, Ibagué, la musical, presenció el desarrollo de la Tercera Convención y de allí en adelante le llamamos Congreso, realizándose el Cuarto en la acogedora ciudad de Barranquilla, en el año de 1959.

Nos encontramos aquí para dar principio a este Quinto Congreso en la Ciudad de las Flores, la capital de este modelo Departamento de Antioquia, Medellín, la iniciadora, donde sus hombres ostentan el esfuerzo arrollador del trabajo organizado y sus mujeres el emporio de sus virtudes.

Sobre los erguidos hombros del profesor Pedro Nel Cardona quedó el peso de la organización de este certamen. No era difícil tarea para él, pues siempre 
está entre los primeros, cuando se trata de evenos científicos nacionales y cuando es necesario representar al país en Congresos Internacionales de la Especialidad.

En unos y otros ha dejado estampado el sello claro de su espíritu de inves-tigación y su amor al estudio.

La Sociedad Colombiana de Obstetricia y Ginecología, que me honro en presidir, trae para usted, doctor Cardona, una expresión de reconocimiento y admiración, por la brillante labor científica desarrollada en su dosencia, por la pulcritud de su ejercicio profesional y por sus dotes de ciudadano ilustre.

La labor de Secretaría General estuvo a cargo del doc:or Fernando Cardona Arango quien le emprimió la misma consagración y briliantez con que enmarca todos sus empeños.

El señor Presidente de la Asociación Antioqueña de Obstetricia y Ginecología, doctor René Díaz Correa, con sus compañeros de Directiva, complementaron esta tarea fecunda, que marca un nuevo hito en el desarrollo científico del país.

Los temas de estos congresos, como es natural, se refieren siempre al estudio de la mujer en la sublime tarea de la maternidad y el análisis de las causas que atentan contra su salud, lo mismo que a la manera de combatirlas.

En lo que se refiere a la maternidad, son muchos los progresos alcanzados en los últimos 10 años, y podemos ufanarnos un poco si contamos con centros asistenciales de organización avanzada y con grupos de profesionales idóneos, que se han esforzado por tecnificar cada día más aquellos centros. Se aplican hoy día conductas precisas que son el fruto de un análisis severo y que han llegado con sus efectos a sitiar y casi a eliminar complicaciones que antes parecían invencibles y que ponían en peligro con inusitada frecuencia la vida de la madre y el hijo.

Una de ellas, la eclampsia, ha sido vigilada muy de cerca y casi rodeada de un halo de seguridad mediante su estudio etiológico. En esta forma se cuida a la mujer gestante con el emblema de la lógica que es la medicina preventiva. Se ha cambiado la convulsión y el trágico gesto en que termina, por un trascurso apasible del embarazo. Estos estudios, hechos también en Colombia, han sido presentados fuera del país por especialistas de las últimas promociones y han sido escuchados con atención por su denso contenido.

El milagro de la sicoprofilaxis es quizá la conquista que más triunfos representa para la medicina. Aprovechando los elementos más nobles con que el Crea- 
dor dotó al ser humano, armoniza la actividad cerebral con la vida muscular, con el don de la palabra amable, del ademán suave, de la persuación, con el dominio de la inteligencia y como toda inteligencia es de origen divino, ha logrado transformar en muchas ocasiones la sentencia de "parirás tus hijos con dolor", en un tranquilo y trascendental acto humano.

La trayectoria de la ginecología también es ascendente y entre sus objetivos destacados están la lucha contra el cáncer y el estudio de la esterilidad conyugal.

En su empeño por librar a la mujer de los tumores malignos, ha emprendido una campaña tenaz para descubrir las primeras células que intenten anarquizar los tejidos, conformando así el diagnóstico precoz, guía casi segura para evitar la cirugía radical o la muerte por invasión de los tejidos.

Cuando el ginecólogo estudia la pareja estéril, pone en juego casi todos los recursos de la fisiología pues ya es convencional el estudio metódico que pone a prueba el funcionamiento de los distintos factores.

Todo esto se practica con devoción en los centros densamente poblados del país pero estamos en la obligación de extenderlos cada vez más, para que las gentes en su mayoría se beneficien con su aplicación.

Al lado de esta forma casi elogiosa como registramos los adelantos de la medicina nacional, debemos colocar la crítica por lo que hemos dejado de hacer, especialmente en el aspecto social.

Es de práctica corriente inscribir el embarazo con la simple anotación de que procede de unión sacramental o de unión libre.

Lentamente se han ido acumulando las cifras escalofriantes de hijos ilegítimos, que incompletas aún, asombran la estadística nacional y amenazan a la sociedad. Muy poco se ha intentado para proteger a la mujer con una educación sexual y advertir al hombre de la responsabilidad que debe asumir. No se conoce o no se pone en práctica una ley que auspicie o proteja el matrimonio prefiriéndolo en la asignación de ocupación oficial o privada. Más aún, a la mujer embarazada o solamente casada se le niega la oportunidad de trabajar para ayudar al sostenimiento de su hogar.

Estas circunstancias han provocado el abandono del niño que legítimo o ilegítimo, ha ido a engrosar rápidamente los escuadrones del robo y la violencia. 
Es tan palpable esta realidad y de unas perspectivas tan cercanas y peligrosas, que me han decidido a tratar este punto y a pedirles que unamos nuestros propósitos por una ayuda que conduzca a la rehabilitación de la mujer y el niño abandonados.

Debemos presentarle al país esta evidencia cruel, con planteamientos de posible solución.

Todos sabemos que del conjunto de hogares se forma la sociedad y la agrupación de sociedades constituye un país. En Colombia parece que la solidez del hogar en una gran proporción ha perdido firmeza. La presencia de desacuerdos menores y de aparentes incompatibilidades mayores, agrietan fácilmente la forma estructural del matrimonio. Las consecuencias de esto son generalmente el hombre frustrado y la mujer que trata de ocultar con vergüenza su abandono, ante la indiferencia de la sociedad y de la ley y a veces la impotencia para luchar por sus hijos.

A la consulta del médico se presenta hoy el hombre o la mujer, a pedir tratamiento para una serie de síntomas localizados unas veces en el aparato digestivo, otros de apariencia circulatoria y otros que buscan la esfera genital. Cumplimos los requisitos clínicos y de laboratorio, pero la medicina que ha sido siempre tan humana, nos aconseja ahora buscar, además, cómo vive ese ser. Esto es para nosotros el esbozo de la ginecología sicosomática, aplicable a las otras ramas de la medicina en el sistema de oír al paciente la narración de su malestar y de su angustia con atención marcada; interroguemos con suavidad y con tino su batalla íntima y encontraremos muchas veces que aquella enfermedad sin pruebas tiene sus garras clavadas en el alma.

Con esto buscamos para nuestro pueblo salud corporal y salud mental. Pidamos a la iglesia católica su atinada intervención para que guíe el desarrollo de la educación sexual en la juventud escolar. Pidamos también a muchos de los que llaman Padres de la Patria que en vez de llevar pistolas al Congreso de la República, a las Asambleas y a los Cabildos, lleven proyectos que traten de contener el desajuste social que amenaza la vida misma del país.

Con esta conjunción de fuerzas de la iglesia, la ley y la medicina, tendremos un país sano en todos sus aspectos para que ocupe con orgullo su sitio en el conjunto de los pueblos civilizados. 